\title{
A filosofia do precedente: reconstrução racional e análise conceitual ${ }^{*}$
}

\author{
The philosophy of precedent: conceptual \\ analysis and rational reconstruction ${ }^{* *}$
}

Pierluigi Chiassoni ${ }^{1}$

Thiago Pádua, Tradutor ${ }^{2}$

Recebido em: 22/05/2016.

Aprovado em: 30/05/2016.

* Publicação original: CHIASSONI, Pierluigi. The philosophy of precedent: conceptual analysis and rational reconstruction. In: BUSTAMANTE, Thomas; PULIDO, Carlos Bernal (Edit.). On the philosophy of precedent: the 24th World Congress of the International Association for Philosophy of Law and Social Philosophy. Beijing, 2009. Proceedings... Stuttgart: Franz Steiner Verlag, 2012. v. 3.

1 Pierluigi Chiassoni é Doutor em Direito (Università di Milano, dottorato di ricerca in "Filosofia analitica e teoria generale del diritto", 1990), Master of Laws (Ll.M. Cornell University, N.Y., U.S.A., 1987), graduado em Direito, com Láurea em Jurisprudência (Università di Genova, 1984). Professor de Filosofia do Direito na Università degli Studi di Genova, e presidente do "Master" em Global Rule \& Constitutional Democracy of LawInstituto Tarello para Filosofia do Direito, ligado a Università di Genova.

2 Traduzido por Thiago Pádua, Doutorando, Mestre e Bacharel em Direito. Professor de Direito Civil I e Instituições Jurídicas - UniCEUB. Pesquisador do Centro Brasileiro de Estudos Constitucionais - CBEC. Advogado. 


\section{Filosofia do precedente: duas variedades bá- sicas}

Os organizadores agradavelmente direcionaram a submissão dos papers sobre a "Filosofia do Precedente", relativos: a) a estrutura dos precedentes jurídicos”, b) suas "fundações filosóficas", c) sua "relevância para a teoria do direito", d) sua "relevância para a prática jurídica”, e, por último, mas não menos importante, e) os "problemas metodológicos” com que os juízes e os juristas se deparam em ordem a "reconhecer", "interpretar" e "seguir os precedentes".

De maneira direta, quaisquer investigações críticas sobre os temas acima referidos, dentro da filosofia do precedente, podem ser de duas espécies diferentes.

Para iniciarmos com o que poderia ser concebido como uma "teoria normativa" sobre o precedente judicial: como uma peça da jurisprudência normativa, ou em um sentido mais amplo, como a velha "ciência da legislação" da filosofia iluminista. Uma filosofia do precedente deste tipo pode ser caracterizada como um "discurso", relativo a uma ordem jurídica estabelecida ou um grupo de ordens jurídicas que pretendam fornecer, e geralmente o fazem, respostas para questões de política legal relativas a maneiras axiologicamente adequadas de (i) compreender os precedentes, (ii) definir sua relevância prática na ordem jurídica (isto é, seu status como fonte do direito positivo, se possuir algum), (iii) definir os princípios que devem integrar a doutrina dos precedentes, e, (iv) lidar com os precedentes a partir do ponto de vista metodológico da interpretação, para seu uso e raciocínio. A adequação axiológica de qualquer de tais teorias depende claramente, em última análise, do pano de fundo permeado por alguma visão ética: geralmente, em alguns princípios de moralidade pública, relativos às instituições jurídicas de uma sociedade bem ordenada, a qual o filósofo está comprometido.

Em segundo lugar, e por outro lado, a filosofia do precedente também pode ser concebida como uma "teoria analítica": uma peça de análise conceitual, em que o elemento central está lidando com a "terminologia”, com os "conceitos", e, em um nível meta-teórico, as "teorias" relativas ao precedente judicial como ligadas a uma determinada cultura jurídica, em ordem a obter melhores terminologias, melhores conceitos e melhores maneiras de se pensar a respeito, do ponto de vista da racionalidade e dos valores, como a clareza, a precisão, a discriminação e a justificação.

Há conexões obvias entre os dois tipos de filosofia do precedente acima referidas. Por um lado, a filosofia normativa do precedente está condenada a falhar - ao habitar o universo retórico dos discursos obscuros, a menos que seja iluminada, e mesmo apoiada, e se necessário, curada, por um equipamento de conceitos claros e distintos, além de visões e modos de pensamento.

Por outro lado, uma filosofia analítica do precedente, para que faça seu trabalho adequadamente, necessita de plena consciência sobre o fato de que o precedente judicial é matéria de alegações, disputas e valores ideológicos.

O presente paper pretende delinear algumas poucas peças da filosofia do precedente a partir da disposição analítica. Tomando pontos de vista de uma análise fragmentada, explanatória, não comprometida axiologicamente, lidarei com três problemas: inicialmente, uma definição analiticamente adequada das noções chaves de ratio decidendi e de obiter dictum; em segundo lugar, uma teoria analiticamente adequada da interpretação judicial dos precedentes (de fato, uma meta-teoria explanatória, como iremos ver); em terceiro lugar, e finalmente, uma teoria analiticamente adequada da relevância prática dos precedentes judiciais.

\section{Alguns quebra-cabeças}

Antes de proceder adiante, entretanto, deixem-me dizer algumas palavras sobre dois assuntos relacionados aos precedentes judiciais, que foi mencionado pela lista dos organizadores, e que eu aparentemente estou descartando na minha inquirição, qual seja: "a estrutura dos precedentes" e sua "fundação filosófica”.

\subsection{Estrutura dos precedentes}

O que é "a estrutura dos precedentes"? Tal questão, muito embora possa parecer uma coisa natural, no entanto é apta a levar a equívocos. Questões mais cautelosas vem em primeiro plano. Os precedentes possuem "uma estrutura"? Existiria mesmo alguma coisa que seria chamada a "estrutura dos precedentes"? Exatamente o que nós estamos procurando, quando perguntamos pela "estrutura dos precedentes"?

Claramente, não podemos fornecer nenhuma resposta razoável para estas questões, a menos que nós 
tenhamos estabelecido previamente, e tornado claro, exatamente o que queremos dizer com a escorregadia frase: "precedente judicial".

Não menos que 3 diferentes candidatos aparecem aqui, embora relacionados. Inicialmente, um precedente judicial pode ser considerado como consistente em uma decisão judicial (i) como um todo - a opinião, incluída a ratio decidendi ou a holding, mais as determinações individuais para o específico caso em análise, (ii) pronunciada em um período de tempo prévio ( $\mathrm{t}^{1}$ ), (iii) satisfatoriamente reportado (isto é, reportado de tal maneira a ser passível de ser utilizado e conhecido no futuro por juristas e juízes trabalhando na jurisdição relativa a ele), e (iv) tendo o mesmo, ou similar (tipo de) fatos e questões como os fatos e questões a serem adjudicadas no tempo presente ( $\mathrm{t}$ ). Isso eu chamarei de precedente-julgamento.

Mais do que isso, um precedente judicial pode ser considerado como consistente, mais estritamente, na base da ratio decidendi - ou holding, de um julgamento pronunciado em um período de tempo prévio $\left(\mathrm{t}^{1}\right)$, satisfatoriamente reportado, e tendo o mesmo, ou similar (tipo de) fatos e questões como os fatos e questões a serem adjudicadas no tempo presente $(\mathrm{t})$. Isso eu chamarei de precedente-holding, ou de precedente-ratio decidendi.

Finalmente, um precedente judicial ser considerado como consistente, novamente de maneira estrita, nas determinações individuais de um julgamento pronunciado em um período de tempo prévio $\left(\mathrm{t}^{1}\right)$, satisfatoriamente reportado, e tendo o mesmo, ou similar (tipo de) fatos e questões como os fatos e questões a serem adjudicadas no tempo presente ( $t$ ). Isso eu chamarei de precedente-ordem.

"Estrutura", entretanto, também é uma palavra escorregadia. A estrutura de alguma coisa pode ser tomada como sendo, a seu turno:

(a) aquela parte de alguma coisa, sem a qual ela simplesmente não se sustenta (sobrevive, subsiste, existe); pense na estrutura de um prédio, em suas vigas-mestras, sua caixa de pilares concretos;

(b) o núcleo (core ou kernel) axiológico de alguma coisa, sua parte essencial, isto é, o componente ou propriedade sem o qual seria inválido de algum ponto de vista relevante;

(c) o grupo de relações adequadas, a rede de comunicações apropriadas entre as várias partes de um todo, sem o qual ele seria empobrecido e defeituoso exemplo de seu tipo;
Claramente, "estrutura" é uma palavra valorativa, provida a partir de um significado (positivo) emotivo: de fato, dizendo de $\mathrm{X}$ que ele pertence a estrutura de algum $\mathrm{Y}$, geralmente fornece a $\mathrm{X}$ uma luz favorável, trazendo para este $\mathrm{X}$ a consideração devida a coisas que são importantes, por alguma razão.

Aparentemente, nós podemos satisfatoriamente investigar sobre a estrutura de um precedente-julgamento, em todos os três significados acima.

Nenhuma peça do discurso judicial (bem construído e devidamente pronunciado) iria se sustentar como um precedente-julgamento se, fornecido um modelo normativo de uma estrutura de "opinião-e-mais-uma-ordem”, ela apenas contiver também a opinião, mas não uma ordem individual qualquer que seja ela, ou uma ordem individual, mas não uma opinião, qualquer que seja ela.

Nenhum precedente-julgamento seria uma instância que valesse a pena (valida e adequadamente), se ela não contiver qualquer holding, assumindo que este seja sua parte essencial, seu núcleo e kernel axiológico (e o mesmo poderia ser dito relativamente à ordem).

Finalmente, nenhum precedente-julgamento seria uma instância que valesse a pena (valida e adequadamente) se, fornecido um modelo normativo de uma estrutura de "opinião-e-mais-uma-ordem", ela contiver uma holding e uma ordem individual, mas elas estiverem totalmente desvinculadas, ou conflitarem umas com as outras.

$\mathrm{O}$ mesmo não pode ser dito relativamente a estrutura, seja quanto ao precedente-holding ou um precedente-ordem.

O que nós podemos referir quando fazemos uma investigação sobre a "estrutura" de um precedente-holding ou da "estrutura" da ratio decidendi?

Assumindo que a ratio decidendi seja uma sentença, utilizando uma linguagem natural, sua estrutura seria seu arranjo sintático. Isso, entretanto, não parece ser ainda um objeto que valha a pena pesquisar - exceto pela a forma gramatical/problema da forma lógica, obviamente. Então, talvez através de uma interpretação caridosa, quando alguém configura uma investigação sobre a "estrutura dos precedentes", e por precedente se entende o precedente-holding, talvez o que aquela pessoa pretenda indagar seja a própria noção de holding, a própria noção de ratio decidendi.

Se este for o caso, contudo, seria uma forma enganosa e obscura de discurso falar em termos de "estrutura 
dos precedentes"; seria melhor descarta-la completamente, e ao invés disso falar sobre, a estrutura dos precedentes-julgamento, ou sobre o conceito (adequado) de holding ou de ratio decidendi.

Obviamente, o conceito adequado de holding/ratio decidendi depende do modelo do investigador sobre o que se compreenda por adequação conceitual. Como dito anteriormente, do ponto de vista de uma filosofia analítica do precedente, estes standards tem a ver com os valores-racionalidades de clareza, precisão, discriminação, etc.

A primeira destas três questões que irei abordar devota-se precisamente a este ponto (confira-se o $\$ 3^{\circ}$ abaixo). Então, de certo modo, eu não descarto realmente a primeira questão proposta pelos organizadores; não obstante, tive de deixar claro o motivo disso.

\subsection{As fundações filosóficas dos precedentes}

Assim como a "estrutura", a "fundação" é outra palavra amada no léxico dos filósofos. A propósito, ela soa, por um lado, técnica e formada por conteúdos preciosos. Assim como "estrutura", entretanto, ela é selada com indeterminação: talvez até mais do que aquela primeira.

Os precedentes possuem "fundações"? Há alguma coisa realmente funcionando como as "fundações filosóficas" dos precedentes? O que procuramos quando nós perguntamos pelas "fundações filosóficas" dos precedentes?

Duas possibilidades podem surgir, para mencionar apenas estas duas, dentre tantas outras, para apontar uma maneira adicional, e mesmo mais ampla de compreender e usar a frase "precedente judicial".

(1) inicialmente, a procura pelas fundações filosóficas dos precedentes pode pertencer à filosofia normativa, prática. Em tal caso, trata-se de uma procura pela justificação. Obviamente, deste ponto de vista, justificação não se refere particularmente ao precedente judicial (julgamento, holding ou ordem). Ao invés disso, refere-se a algum sistema de precedentes, real ou imaginário. Exemplificativamente, pode estar relacionado: (a) a algumas práticas dos precedentes, contextualizadas e descritas (estabelecendo, utilizando, interpretando, aplicando, seguindo, modificando, expandindo, desconsiderando, superando, etc.), em uma ordem legal certa e determinada; (b) a alguma doutrina ideal dos precedentes judiciais, contextualizadas e descritas (estabelecendo, utilizando, interpretando, aplicando, seguindo, modificando, expan- dindo, desconsiderando, superando, etc.), para uma ordem legal certa e determinada;

"Fundações", assim como sua palavra irmã "bases", é claramente metafórica; "justificação", não. Esta última deve substituir aquela primeira em um discurso filosófico cuidadoso.

(2) a busca pelas fundações filosóficas do precedente pode também pertencer à filosofia analítica. Em tal caso, seria uma procura por melhor compreensão da instituição, da doutrina e da prática do precedente judicial, assim como existentes em alguma cultura jurídica.

De um ponto de vista analítico, uma tal melhor compreensão pode ser garantida de maneiras distintas e conspiratórias, mutuamente ligadas, especialmente: (a) livrando-se de formas discursivas equivocadas; (b) trabalhando um equipamento conceitual mais preciso, com a saída de um grupo de reconstruções racionais, com as fronteiras conceituais definidas pelos usos linguísticos; (c) considerando as pressuposições contextuais do andamento conceitual e arranjos terminológicos: o quanto isso está enraizado, e os espelhos, na escala ideal do assento filosófico, (i) a natureza das instituições jurídicas na maneira de seu desenvolvimento histórico, (ii) a natureza das instituições e sociedades humanas, (iii) a natureza do homem como fator constitutivo disso tudo; (d) imaginando quais partes do prosseguimento conceitual e do equipamento terminológico deveriam permanecer, e quais delas, ao invés disso, deveria ser diferentes, assumindo que as diferenças momentâneas deveriam estabelecer relação com a natureza das instituições jurídicas, com a natureza das sociedades humanas e com a natureza do homem; (e) imaginando novos equipamentos terminológicos e conceituais para procurar, (e/ou trabalhar com) as reais instituições e as práticas do precedente judicial, assim como o conhecemos.

Eu descartei a procura pela justificação prática e normativa do sistema de precedentes, optando por uma aproximação analítica. Contrariamente, não obstante as aparências, a busca por uma melhor compreensão é novamente uma das metas que tentarei alcançar no presente paper; de fato, isso pode estar relacionado, neste sentido, com as fundações filosóficas dos precedentes (como iremos ver nos $\$ \$ 3,4$ e 5 , a seguir).

\subsection{A relevância do precedente judicial para a teoria do direito}

As teorias jurídicas se preocupam com os pre- 
cedentes judiciais? Elas deveriam se preocupar? Claramente, ambas as questões ordenam respostas positivas, se endossarmos uma concepção normativa de teoria do direito (teoria do direito como jurisprudência normativa), ou uma concepção analítica (teoria do direito como jurisprudência analítica).

Isto é o suficiente para observações preliminares. Caminhemos, agora, para três questões que mencionei inicialmente.

\section{Ratio decidendi: obiter dictum}

Aparentemente, nos deparamos uma verdade triste: após séculos de investigações, juristas e teóricos do direito parecem ainda estar à procura da concepção adequada de ratio decidendi.

Por que isso é assim? Provavelmente, devido a uma combinação condenada a ser um sucesso permanente de esforços de pensamento não muito claro aliado aos comandos da política judiciária, ideologia jurídica e guerrilha metodológica.

Seja como for, mesmo uma pesquisa mais ou menos superficial sobre as noções de ratio decidendi, assim como definida pelas literaturas acadêmicas do civil law e do common law, iria resultar em uma invenção de múltiplas cabeças. Poderíamos encontrar, por exemplo, que a ratio decidendi foi caracterizada, a seu turno, da maneira seguinte:

(RD1) o elemento na opinião que representa a premissa necessária, ou o passo lógico necessário, para a decisão de um caso.

(RD2) o princípio jurídico que, em uma decisão judicial, é suficiente para decidir o caso sob análise.

(RD3) a argumentação necessária, ou suficiente, para decidir um caso sob análise.

(RD4) a norma (regra, princípio) que representa, alternativamente: (a) a condição necessária e suficiente, (b) a condição suficiente, mas não necessária, ou mesmo, (c) qualquer condição necessária, mas não suficiente, da decisão do caso sob análise.

(RD5) a norma para os fatos da causa que, como análise textual divulgada do precedente-julgamento, o juiz que decidiu o caso efetivamente estabeleceu e/ou seguiu, atrás do que ela deveria ter estabelecido ou pensou ter estabelecido.
(RD6) a norma para os fatos do caso que o juiz que os pronunciou expressamente declarou estabelecer e/ou seguir, ou tacitamente acreditou ter estabelecido ou seguido.

(RD7) a norma para os fatos de um caso que o juiz expressamente ou tacitamente tratou como necessários para decidir um caso.

(RD8) a norma dos fatos relevantes de um caso que - de acordo com o direito existente, fatos e precedentes - o juiz que decidiu o caso deveria ter estabelecido e/ou seguido, em ordem a decidir apropriadamente o caso.

(RD9) a norma para os fatos relevantes de um caso que, de acordo com o juiz subsequente $\left(\mathrm{J}_{\mathrm{s}}\right)$, o juiz prévio $\left(\mathrm{J}_{\mathrm{P}}\right)$, que decidiu o caso, acreditou ter estabelecido e/ou seguido.

(RD10) a norma para os fatos relevantes de um caso que, de acordo com o juiz subsequente $\left(\mathrm{J}_{\mathrm{S}}\right)$, o juiz prévio $\left(\mathrm{J}_{\mathrm{P}^{\prime}}\right)$, que decidiu o causo, efetivamente estabeleceu e/ou seguiu, não importando o que ela tenha pretendido significar.

(RD11) a norma para os fatos relevantes de um caso que os juízes subsequentes $\left(\mathrm{J}_{\mathrm{ss}}\right)$ deveriam ter considerado como tendo sido estabelecidas e/ou seguidas pelo juiz prévio $\left(\mathrm{J}_{\mathrm{P}}\right.$, no relevante precedente-julgamento.

Todas as noções de ratio decidendi relatadas acima, claramente são indeterminadas, embora através de diferentes níveis. Parece ser necessário, por consequência, buscar noções mais precisas e claras para algum trabalho de reconstrução racional. Antes disso, entretanto, alguns comentários parecem necessários.

1. As várias noções acima referem-se a (ou propõe-se a) algumas distinções entre conceitos e tipos de rationes decidendi, relativos a:
(a) sua natureza;
(b) seu modo de expressão;
(c) a relevância da intenção do juiz que os es- tabeleceu e/ou os aplicou (os "seguiu") para decidir um caso;
(d) sua relevância objetiva para a decisão do caso;
(e) sua posição sistêmica;

Por natureza da ratio decidendi existem basicamente duas concepções em jogo, não necessariamente em desacordo.

2. Por um lado, as rationes decidendi algumas ve- 
zes são caracterizadas como razões, premissas, passos logicamente necessários, argumentação necessária ou suficiente de um precedente-julgamento (como é o caso, por exemplo, das noções RD1 e RD3). Esta é a concepção argumentativa da ratio decidendi.

Lado outro, as rationes decidendi também são caracterizadas como normas, regras, princípios e determinações (veja-se, por exemplo, RD2, RD4, etc.). Esta é a concepção normativa da ratio decidendi.

A propósito, ambas as concepções encontram suporte na palavra latina "ratio", cuja semântica inclui tanto a ideia de "razão", quanto a ideia de "determinação" (medir, um critério de julgamento).

A norma geral aplicada pelo juiz para decidir um caso é uma "razão" (a razão normativa) que justifica aquela decisão. Da mesma maneira, ela também é uma premissa (a premissa normativa) do raciocínio da conclusão da qual é a ordem judicial. Finalmente, se olharmos para qualquer julgamento como uma peça de raciocínio provida por uma estrutura lógica, a norma geral aplicada pelo juiz também, pode ser considerada como o passo lógico necessário (passo lógico normativo) do raciocínio.

Portanto, a concepção normativa de ratio decidendi está perfeitamente em sintonia com a concepção argumentativa. Isso conduz, entretanto, a noções mais determinadas.

De acordo com um ponto de vista mais analítico, noções normativas devem ser preferidas em detrimento das noções argumentativas. Assim, seria melhor considerar a ratio decidendi como norma, princípio ou determinação que ocupam papel fundamental (fiquemos satisfeitos, por enquanto, com essa expressão) na justificação de uma decisão judicial.

1. Como modo de expressão da ratio decidendi, a distinção básica das várias noções acima parece estar entre razões explícitas e implícitas.

Uma ratio decidendi é explícita quando foi estabelecida com uma formulação discreta: quando ela foi expressada, estipulada ou (como algumas vezes se diz) "anunciada" pelo juiz na opinião da procedente-julgamento.

Em sentido oposto, uma ratio decidendi é implícita quando ela é a premissa normativa tácita do raciocínio judicial: quando ela não foi formulada, estipulada, anunciada, muito embora - alguém pode dizer - tenha sido estabelecida e aplicada para decidir o caso.
No devido contexto, a ratio decidendi implícita (presumida) de um precedente-julgamento pode ser jogada contra a sua ratio decidendi explícita (presumida). De fato, pela combinação desta distinção com a distinção adicional, relativa a relevância objetiva da ratio, entre a ratio real e a ratio aparente, alguém pode arguir, por exemplo, que a ratio explícita de um precedente-julgamento, embora cuidadosamente formulada pelo juiz, é apenas uma impostura; ela é apenas a ratio aparente, a qual deve ser invertida para que nas decisões judiciais subsequentes se preste o devido respeito a ratio real (em termos de ser tácito, implícito, não-formulado, não-anunciado).

De um ponto de vista analítico, as duas distinções - ratio implícita vs. ratio explícita, e ratio real vs. ratio aparente - valem a pena de serem mantidas em mente, acima de tudo pelo seu uso como ferramentas práticas na arte de raciocinar com os precedentes.

Entretanto, uma ressalva deve ser realizada. Para que faça sentido a partir de uma perspectiva analítica, a distinção entre ratio decidendi explícita e a ratio decidendi implícita deve ser refundida de uma tal maneira que um procedimento razoavelmente objetivo deve ser seguido para identifica-los, se houver alguma, como um resultado de uma análise textual de um precedente-julgamento. Isso sugere o apelo para a ideia de uma estrutura lógica das decisões judiciais, como veremos a seguir.

2. Algumas vezes a noção de ratio decidendi é definida de tal maneira a se tomar em conta a intenção (presumida) do juiz que pronunciou o precedente-julgamento (conforme, por exemplo, RD6, RD7, RD9), e algumas vezes, entretanto, esse não é o caso (como p. exemplo RD1, RD2, RD3, RD4).

A noção daquele primeiro tipo, nós podemos chamar de noção intencionalista, ou subjetiva, de ratio decidendi: neste ponto, a ratio é uma ratio pretendida, daquele tipo que o juiz pretende estabelecer ou aplicar.

A noção desta última, pelo contrário, podemos chama-la de noção de ratio decidendi "des-psicologizada", ou "objetiva": neste ponto, a ratio é identificada (e relacionada) como um objeto puramente não intencional, como uma peça do discurso do significado, sentido ou valor o qual deve ser identificado e apreciado sem que se faça qualquer referência, ou preste qualquer atenção à intenção (propósito, crenças e atitudes) de seu autor.

A noção de ratio decidendi definida pelos juristas 
do civil law geralmente são objetivas; em sentido contrário, as noções definidas por seus colegas do common law são frequentemente subjetivas.

A distinção entre as noções objetivas e subjetivas de rationes decidendi são relevantes de duas perspectivas relacionadas.

Por um lado, isto é, ao menos aparentemente, o núcleo de dois grupos distintos de modelos relacionados à “interpretação dos precedentes": modelos subjetivos (ou ao invés disso, mixada) e objetivos (como iremos observar mais à frente).

Por outro lado, a distinção possui um uso argumentativo, como aqueles que eu considerei no item anterior. A propósito, no devido contexto, um pode agir no papel de ratio subjetiva (presumida) de um precedente-julgamento contra a sua ratio objetiva (presumida) (este modo de proceder é sugerido, com efeito, pelas noções RD5 e RD10 acima), postulando, por exemplo, que o primeiro seria apenas a ratio aparente, enquanto o segundo seria a ratio real.

3. Algumas vezes a noção de ratio decidendi é definida de tal maneira a incluir uma referência a sua posição sistemática (confira-se, por exemplo, RD8, RD11). Aqui, mais precisamente, o que está sendo decidido é uma "noção não vaga", vale dizer, uma noção da ratio decidendi correta, adequada ou precisa, para um caso.

O uso básico para esta noção pertence claramente ao criticismo, tanto por juízes de apelação quanto por procuradores de algum caso erroneamente decidido em um precedente-julgamento.

Como eu disse anteriormente, do ponto de vista da filosofia analítica do precedente, os próximos passos, seguinte às indagações prévias, devem ser voltados para a definição - reconstrução racional - de alguma noção de ratio decidendi, de uma tal maneira a fornecer aos procuradores e juízes (alegadamente) um melhor conjunto de conceitos.

Tendo em conta a presença das noções objetiva e subjetiva de ratio decidendi no pensamento jurídico, e tendo em mente a necessidade de afastar a indeterminação na identificação da ratio com precedentes-julgamentos (por exemplo, "curar a conversa solta" em termos de "condições" "suficientes" e/ou “necessárias"), uma reconstrução analítica, para que seja de algum uso, deve encontrar os seguintes requisitos:
1) ela deve incluir três conceitos de ratio decidendi: um objetivo, um subjetivo e um conceito misto - eventualmente para que os juristas e juízes escolham um deles para adotá-lo em sua prática, também levando em conta a sua história, sua cultura jurídica e seus propósitos.

2) ao definir o conceito objetivo, deve-se fazer referência à estrutura lógica das decisões judiciais; tal estrutura deve ser concebida, a seu turno, em sua forma mínima, como um modus ponens normativo, onde a conclusão categórica normativa individual (a ordem judicial) siga a partir de uma premissa geral normativa e condicional (a norma geral aplicada) e uma premissa individual categórica qualificada, ou subjuntiva.

3) esta maneira de proceder, que remonta a antiga ideia - velha de séculos atrás, de silogismo individual, deve rejeitar cuidadosamente qualquer formalismo ou logicismo, relativo as decisões judiciais; a ideias de que precedentes-julgamentos possuem uma estrutura lógica, a propósito, não implica, por si mesmo, nenhum comprometimento com a visão equívoca de que o raciocínio judicial seja um raciocínio puramente lógico derivado de premissas evidentes. Pelo contrário, como magistralmente demonstrado por Jerzy Wróblewski e Robert Alexy, a ideia de estrutura lógica de uma decisão judicial (na terminologia original de Wróblewski: a ideia de uma “justificação interna” da decisão judicial) é apenas uma ferramenta útil de análise e crítica das decisões judiciais, que é perfeitamente compatível com a visão de que as premissas da justificação interna das decisões são escolhidas pelo juiz, muito embora elas devam ser providas com alguma justificação (justificação externa).

Com essas observações em mente, os três conceitos de ratio decidendi podem agora definidos, em tentativa, da seguinte maneira:

Ratio decidendi (conceito objetivo) $=$ Df. A norma geral (regra, princípio ou determinação) que tanto está expressa na sentença, no texto de um precedente-julgamento, ou implicitamente nele; é a ratio decidendi de um caso em ralação a certas questões a serem decididas, se (e apenas se) ela for a premissa geral normativa do "modus ponens" ${ }^{\prime 3}$ inferencial, do qual, juntamente com ao menos

O modus ponens clássico, ligado à lógica, e para determinar a validade da afirmação, possui a seguinte propriedade: 1) se as premissas são verdadeiras, e (If the premises are true, and) 2) a regra é aplicada corretamente, (the rule is applied correcly)

3) A conclusão necessariamente deve ser verdadeira. (the conclusion must necessarily be true). MOHANAN, K. P; 
mais uma premissa (a premissa de subsunção individual), da qual a ordem judicial pode ser derivada.

Note que este conceito não afasta duas situações as quais podem ocorrer na prática, e devem ser brevemente consideradas.

(1) inicialmente, pode acontecer de a mesma ordem judicial ser derivada, no texto da decisão judicial, de diferente (embora convergente) modus ponens inferenciais. Neste caso, haverá tantas rationes decidendi quantas forem as diferentes as diferentes (embora convergentes) modus ponens inferenciais escoradas. Em tal situação, haverá uma pluralidade de diferentes (embora convergentes) inferências de primeiro grau de modus ponens, e consequentemente, uma pluralidade de diferentes (embora convergentes) rationes decidendi de primeiro grau.

(2) além disso, também pode acontecer de a estrutura lógica das decisões judiciais ser um elo de vários modus ponens inferenciais interconectados, onde as premissas gerais normativas das inferências de grau inferior sejam, ao mesmo tempo, a conclusão geral normativa da inferência de grau superior. Em tal caso, nós devemos distinguir por exemplo, com a estrutura lógica de um precedente-julgamento, uma modus ponens inferencial de primeiro grau, uma modus ponens inferencial de segundo grau, uma modus ponens inferencial de terceiro grau, (...) e assim por diante, até a maior e mais alta modus ponens inferencial. Em uma situação como esta, há inúmeras ratio decidendi, do ponto de vista lógico: do mais baixo e menos abstrato, trabalhando como premissa normativa do modus ponens inferencial de primeiro grau, subindo para o mais alto, e mais abstrato, funcionando como premissa normativa do modus ponens inferencial de ultimo grau.

Em ambos os casos, nos quais a ratio decidendi, misturada com vários argumentos identificados na base da estrutura lógica da decisão, deve ser tratada como provida com valor "precedencial", não sendo alguma coisa que a estrutura lógica, enquanto tal - e nem este conceito de ratio decidendi -, possa dizer. Apenas uma doutrina do precedente - fornecendo algum critério de política-legal - pode fazer aquele trabalho. Nos países de common law,

MOHANAN, Tara. Resoning. p. 7. a propósito, um tal critério parece ser precisamente a intenção do juiz: isso traz, em primeiro plano, o conceito subjetivo e mixado de ratio decidendi.

Ratio decidendi (conceito subjetivo) = Df. A norma geral (regra, princípio ou determinação) que tanto está expressa na sentença, no texto de um precedente-julgamento, ou implicitamente nele; é a ratio decidendi de um caso em ralação a certas questões a serem decididas, se (e apenas se) o juiz que decidiu o caso intencionou que ele fosse (a) a estipulação jurídica fundamental ${ }^{4}$ para a decisão concreta do caso sub análise, e, (b) provida com valor "precedencial" para os casos subsequentes.

Ratio decidendi (conceito mixado) $=$ Df. A norma geral (regra, princípio ou determinação) que tanto está expressa na sentença, no texto de um precedente-julgamento, ou implicitamente nele; é a ratio decidendi de um caso em ralação a certas questões a serem decididas, se (e apenas se): (a) ela for a premissa geral normativa do " $\boldsymbol{m o}$ dus ponens" inferencial, do qual, juntamente com outras premissas, a ordem judicial que pode derivada; (b) o juiz que decidiu o caso intencionou que ele fosse (b1) a estipulação jurídica fundamental ${ }^{6}$ para a decisão concreta para o caso, e, (b2) provida com "valor precedencial" para as decisões subsequentes.

Claramente, do ponto de vista da certeza e da controvérsia sobre a identificação da ratio decidendi de um caso, os conceitos misto e subjetivo situam-se em pior situação do que o conceito objetivo. Isto se dá, entretanto, pelo conceito objetivo ser definido de uma tal maneira a deixar o problema do "valor precedencial" de lado. Os outros dois conceitos, por outro lado, levam em conta também este importante problema.

Juntos, os três conceitos trazem luz às fronteiras entre a análise lógica, por um lado, e do outro, a política e os padrões jurídicos: eles mostram a que ponto a análise lógica pode auxiliar a iluminar o caminho e onde alguma doutrina do precedente deve pisar.

Do ponto de vista da filosofia analítica do precedente, evidentemente, os poderes limitados da análise lógica não representam de nenhuma maneira uma desvantagem. Pelo contrário, tudo é atribuído ao seu devido

Sem equivalência específica, o original menciona: "Paramount legal prescription", que nos pareceu mais adequado, pelo contexto, em traduzir por "estipulação jurídica fundamental".

5 Confira-se a nota equivalente acima, no conceito objetivo de ratio decidendi.

6 Confira-se a nota equivalente acima. 
lugar (unicuique suum); além disso, as doutrinas do precedente se tornam um objeto mais relevante para investigação analítica e para uma reconstrução racional.

Ratio decidendi geralmente é oposta ao obiter dictum: a mesma peça de julgamento não pode ser, ao mesmo tempo, e a partir da mesma perspectiva conceitual, ratio decidendi e obiter dictum. Tendo fornecido alguns conceitos do primeiro, o último deve ser definido negativamente, como nenhuma coisa em um precedente-julgamento, que não é uma ratio decidendi de acordo com os conceitos objetivo, subjetivo e misto de ratio decidendi.

\section{Interpretando os precedentes}

O que exatamente nós interpretamos quando "interpretamos os precedentes"? Como fazer, agir ou pensar quando procedemos como "interpretando os precedentes"?

Eu penso que alguns pontos devem ficar claros, antes de procederemos a uma investigação sobre tais questões.

1) Do ponto de vista da relação entre interpretação e a ratio decidendi de um caso, três tipos diferentes de situações podem ser separadas para análise.

2) No primeiro tipo de situação, a ratio decidendi é o resultado de uma interpretação de um precedente-julgamento.

3) No segundo tipo de situação, a ratio decidendi é, ao invés disso, em si mesma, o objeto ou assunto de uma série de um conjunto operações de interpretação textual (que podem assim ser chamadas).

4) Na terceira, e final espécie de situação, a ratio decidendi é - novamente, em si mesma, o objeto ou assunto de um conjunto de operações de interpretação meta-textual (que podem assim ser chamadas).

5) A maioria das técnicas tradicionais do common law para lidar com os precedentes são, de fato, técnicas relativas tanto a interpretação textual ou meta-textual de uma ratio decidendi de um caso previamente determinado, como poderemos observar adiante.

6) Algumas vezes observamos acadêmicos falando de "determinar a ratio decidendi de um caso". De um ponto de vista analítico, tal frase é altamente indeterminada. A propósito, dependendo do contexto, ela pode se referir indiscriminadamente aos três grupos de operações acima referidas (interpretação textual de um precedente-julgamento, interpretação textual e interpretação meta-textual da ratio decidendi), ou apenas a algum deles.

\subsection{Interpretando a ratio decidendi: técnicas textuais}

As técnicas de interpretação textual da ratio decidendi são adequadas para (re)interpretações (o que se assume ser o caso) do sentido original (e do escopo normativo) de uma ratio decidendi previamente identificada. ${ }^{7}$

Para deixar este ponto claro, parece útil introduzir a distinção entre interpretação corretiva e interpretação declaratória da ratio decidendi.

A interpretação declaratória busca estabelecer o sentido correto e o escopo normativo da ratio decidendi, basicamente em duas situações distintas: (a) quando o sentido original se mostrou indeterminado; (b) quando o sentido original tenha sido alegadamente reconstruído de forma equivocada por outro juiz em uma decisão prévia. Neste ponto, os juristas do common law falam de uma "reconstrução", "mensuração" e/ou "explicação" de um precedente.

Uma interpretação corretiva, pelo contrário, busca enfrentar uma presumida discrepância entre a ratio decidendi real e a ratio decidendi aparente. Neste ponto, a ratio previamente identificada, aparente, isto é, a "prima facie ratio" estabelecida por uma leitura superficial de um precedente-julgamento e/ou pela opinião pública, está sendo (re)interpretada, para se ajustar com a ratio presumidamente real e correta: isto significa, a seu turno, que a ratio aparente geralmente precisa estar, tanto amassada (narrowed) ou diminuída (downsized) (por meio de uma "interpretatio restrictiva") - em que os procuradores do common law falam em "refinar", "deduzir", "confinar", "podar", "nuanças", e até mesmo, novamente, "mensuração" da ratio decidendi - ou ao invés disso, "estender" (por meio de uma "interpretatio extensiva") - "estendendo", "perdendo".

\subsection{Interpretando a ratio decidendi: técnicas meta- -textuais}

As técnicas meta-textuais de interpretação da ra-

Por esta razão e pela próxima seção, encontrei um catálogo do common law, embora totalmente desestruturado, em G. Marshall, "Trentaré cose che si possono fare com i precedenti. Um dizionario di common law (1996) 6 Ragion Pratica, $29 \mathrm{ff}$. 
tio decidendi, por contraste, quedam-se basicamente em dois grupos.

Por um lado, existem as técnicas relativas ao uso de um precedente-ratio estabelecido para enfrentar um caso de primeira impressão: isto envolve, geralmente, procedimento por analogia a partir da ratio estabelecida para uma nova ratio relativa ao novo caso examinado. ${ }^{8}$

Por outro lado, existem técnicas relativas a questão do "valor precedencial-institucional" de uma ratio decidendi previamente identificada: eles lidam com o fato de possuírem ou não a força da premissa normativa adequada, como um caso individual em análise, naquele exato momento.

Algumas dessas técnicas pretendem apagar, enfraquecer ou alternativamente, esticar a autoridade de um precedente-ratio. Neste ponto, juristas do common law utilizam algumas operações, como por exemplo: (a) dictum-cantarolando (isto é, dizendo que a ratio não é realmente a ratio, mas um mero dictum), (b) minar a ratio (clamar que não existem razões para que se toma a ratio como autorizativa), (c) per-incuriam-ing (dizer que a ratio fora pronunciada fora de engano), (d) alardeando (dizer que a ratio foi pronunciada para um mero experimento, sem que houvesse a séria intenção de que fosse possuidora de valor precedential), (e) quondam-ing (dizendo que a ratio fora pronunciada há muito tempo atrás, e por evidente, muitas coisas teriam mudado desde então...) (f) ornamentando (apresentando a ratio sob uma melhor luz do que a de costume), e, (g) tranquilizar (apresentar a ratio como como parte da linha enraizada das decisões).

Outras técnicas de interpretação meta-textual intencionam, ao invés disso, se livrar do precedente-ratio, significando com isso que muito embora certamente provido de "valor precedencial", ele não poderia ser aplicado a um específico caso sob análise.

Dentre dessas técnicas de neutralização do prece-

8 Algumas vezes alega-se que a essência de raciocinar com os precedentes é o raciocínio analógico. Esta sugestão, entretanto, precisa ser resistida. O papel da analogia, de fato, auxilia a enxergar quando os fatos de um determinado caso são os mesmos, ou parecidos com o tipo de fatos regados por um precedente-ratio. Mas isso, importante como possa parecer, não exaure nem as técnicas do raciocínio do common law, nem captura da fundação axiológica da autoridade dos precedentes. Neste sentido, confira-se SCHAUER, Frederick. Why precedent in law and elsewher is not totally or even substaintially: about analogy. Perspectives on Psychological Science, v. 3, n. 6 p. 454-460, 2008. dente-ratio, o distinguishing possui papel central. Existem, possivelmente, dois diferentes tipos de distinguishing: a saber, interno (ou regra-distinguishing) e o externo (ou de facto- distinguishing).

O distinguishing externo é a técnica demonstrativa de que o precedente-ratio não deve ser aplicado ao caso examinado pois, no presente caso, os fatos materiais são distintos daqueles englobados pela ratio - muito embora, à primeira vista eles possam ter parecido similares com os fatos decididos pelo precedente-ratio. Neste ponto, o jurista modifica a descrição prévia dos fatos da causa, clamando duramente que todas as coisas consideradas são substancialmente/materialmente diferentes dos fatos que foram governadas pelo precedente.

Pelo contrário, o distinguishing interno é a técnica demonstrativa de que um precedente-ratio não deve ser aplicado ao caso examinado pois, através de uma leitura cuisadosa, os fatos materiais englobados pela ratio seriam diferentes do que pareciam ser à primeira vista, e consequentemente seriam diferentes dos fatos materiais do caso sob análise. Neste ponto, por consequência, os fatos materiais do caso atual permanecem, enquanto o jurista altera a descrição dos fatos relevantes regrados pelo precedente (material e substancialmente).

O distinguishing externo deixa o precedente-ratio incólume, embora conduza a sua não aplicação de um casosob análise. Por sua vez, o distinguishing interno é uma forma de (re)interpretação do precedente-ratio. Ele pertence, consequentemente, as técnicas textuais de interpretação da ratio decidendi; aparentemente, algumas vezes ele é transportado sob o rótulo de "confinando um precedente".

\subsection{Modelos para determinação da "ratio decidendi" de um caso.}

Situações onde a ratio decidendi é o resultado de uma interpretação de uma decisão judicial (isto é, do texto de um julgamento como um todo) são geralmente considerados por modelos: modelos normativos - vagamente representados como concernentes a "interpretação dos precedentes".

Duas famílias de tais modelos podem ser separadas.

Por um lado, há os modelos do common law: como, por exemplo, os bem conhecidos modelos de Eugene Wambaugh, Arthur Goodhart e Rupert Cross. Eles são intencionalistas, modelos mixados, onde a contribuição interpretativa da estrutura lógica da decisão judicial 
não é abertamente reconhecida, ou localiza-se num padrão.

Por outro lado, há os modelos do civil law ou modelos continentais: como, por exemplo, os modelos que podem ser derivados das obras de Jerzy Wróblewski e Robert Alexy concernentes a justificação das decisões judiciais. Eles são modelos objetivos, completamente "despiscicologizados" onde a estrutura lógica das decisões judiciais é a estipulação jurídica fundamental.

\section{Explicando a relevância prática dos prece- dentes judiciais}

Como é sabido, frases como "força persuasiva" (persuasive force), "força vinculante" (binding force), "força vinculante horizontal" (horizontal binding force), "força vinculante vertical" (vertical binding force), "força persuasiva de facto" (de facto persuasive force), "vinculação formal" (formal bindingness)", etc., geralmente são utilizadas para destacar a relevância prática dos precedentes judiciais, ou mais precisamente, da ratio decidendi dos precedentes-julgamento.

Nesta parte final do meu paper, sempre por meio da abordagem de algumas peças de uma filosofia analítica dos precedentes, continuarei a proceder da forma seguinte.

Primeiro, lidarei com algumas distinções - básicas, sob meu ponto de vista.

Segundo, brevemente reportarei o que aparenta ser, até agora, a mais sofisticada tentativa de lidar com a relevância prática dos precedentes, isto é, aquela que os acadêmicos do círculo de Bielefeld performaram.

Terceiro, e para concluir, fornecerei uma consideração alternativa de sistemas jurídicos ideais típicos, considerados do ponto de vista da relevância jurídica (de iure) dos precedentes, se houver algum.

\subsection{Algumas distinções básicas}

Relativamente à relevância prática dos precedentes judiciais - se por tal frase quisermos dizer, de uma maneira bastante ampla e descompromissada, a relevância dos precedentes judiciais para a prática da tomada de decisão judicial e da adjudicação; a distinção básica é desenhada e corre entre a relevância formal (de iure) e a relevância empírica (de facto).

A relevância formal, ou de iure, é uma questão de normas jurídicas: de relevância institucional, consti- tuída e regulada por normas legais (princípios, regras e padrões). Mais precisamente, sua relevância é determinada por normas legais, em graus e maneiras (sobre força, influência, importância e consideração), pelas normas jurídicas que os precedentes judiciais, como definidos e de acordo com o direito positivo, podem, ou devem possuir, enquanto decidirem casos subsequentes iguais ou similares, em um período determinado (t), em um específico sistema legal (SL).

Ao contrário, a relevância empírica, ou de facto, é uma questão de fatos: é a relevância (força, influência, importância ou consideração) que de fato os precedentes judiciais (de algum tipo) possuem na decisão de casos subsequentes, iguais ou do mesmo tipo, em um período determinado (t), em um específico sistema legal (SL).

As relevâncias empírica (de facto) e formal (de iure) não necessariamente estão em desacordo: aliás, elas apontam para aspectos logicamente independentes do mundo jurídico - embora não necessariamente desvinculados. Deste ponto de vista, podemos distinguir três tipos de relevância empírica (ou de facto): 1) secundum legem, 2) contra legem, e 3) praeter legem.

Relevância empírica secundum legem: A relevância de fato do precedente, qualquer que seja ele, é o efeito de ser seguido por juízes dos precedentes relativos as normas do direito positivo, de sua crente fidelidade à doutrina do precedente positiva.

Relevância empírica contra legem: A relevância de fato do precedente, qualquer que seja ele, é o efeito de que os juízes possam romper as normas legais positivas relativas aos precedentes, de sua violação à doutrina do precedente positiva.

Relevância empírica praeter legem: Por hipótese, o direito assumidamente não dirá nada sobre a relevância judicial dos precedentes, e será, com efeito, indiferente com relação a ele. Em tal situação, a relevância de facto dos precedentes, qualquer que sejam eles, é o efeito da prática judicial extra ou praeter legem: por ele ter sido estabelecido fora do direito positivo, possivelmente (mas não necessariamente) seguindo alguns modelos judiciais normativos de boas práticas judiciais apoiadas pela opinião pública da cultura jurídica.

Acadêmicos geralmente se referem aos precedentes como possuindo força persuasiva, em oposição aos precedentes possuidores de força vinculante (binding force).

Algumas vezes, a distinção intenciona similaridade com a distinção entre a relevância empírica (de facto) e 
a relevância formal (de iure) dos precedentes. Precedentes possuindo força persuasiva teria relevância meramente empírica (de facto), e geralmente, poderíamos dizer, relevância de facto praeter legem; enquanto por outro lado, ao contrário, precedentes possuidores de força vinculante (binding force) teria relevância formal (de iure).

Entretanto, algumas vezes a distinção entre a força persuasiva e força vinculante dos precedentes parece se referir a duas formas diferentes da relevância formal (ou de iure) dos precedentes judiciais.

De um ponto de vista analítico, confusões devem ser evitadas, evidentemente.

Uma distinção final, que como as anteriores, pertence a presente teoria dos precedentes entre a relevância vertical e a relevância horizontal dos precedentes judiciais. Neste ponto, também, pode ser válido, para o bem da clareza, combinar esta distinção com divisão básica da relevância de facto/de iure: muito embora na maior parte do tempo a distinção refira-se as duas formas da relevância formal (de iure) e da relevância empírica (de facto) dos precedentes.

\subsection{0 círculo de Bielerfeld}

Os acadêmicos do círculo de Bielefeld (Aulis Aarnio, Robert Alexy, Zenon Bánkowki, Gunnar Bergholtz, Svein Eng, Francisco Laporta, Neil MacCormick, Geoffrey Marshall, Lech Morawski, Enrico Pattaro, Aleksander Peczenik, Alfonso Ruiz Miguel, Robert Summers, Michele Taruffo, Michael Troper, Marek Zirk-Sadowski, etc. $\left.{ }^{9}\right)$ trabalharam uma consideração teorética sobre a relevância prática dos precedentes (melhor dizendo: relevância prática das rationes decidendi dos precedentes-julgamento), onde eles separaram quatro formas básicas de relevância:

1) vinculação formal.

2) força persuasiva de facto.

3) força justificatória complementar.

4) meramente ilustrativa - ou outro valor parecido ${ }^{10}$.

MACCORMICK, Neil; SUMMERS, Robert S. (Ed.). Interpreting precedents: a comparative study. Ashgate: Dartmouth, 1997. p. 52.

10 MACCORMICK, Neil; SUMMERS, Robert S. Apendix: final version of the common questions, comparative legal precedent study, september 1994, In: MACCORMICK, Neil; SUMMERS, Robert S. (Ed.). Interpreting precedents: a comparative study. Ashgate: Dartmouth, 1997. p. 554-555; uma visão ampla do escopo consta do ensaio de PECZENIK, A. The binding force of precedent. In: MACCORMICK, Neil; SUMMERS, Robert S. (Ed.). Interpreting prec-
1. Vinculação formal = Df. "viola o direito um julgamento que não respeita a vinculação do precedente, e portanto, é passível de ser revertida em apelação".

Três graus de vinculação formal são separados:

(1a) precedente vinculante estrito (strictly): os precedentes são estritamente vinculantes, qualquer que seja seu assunto, nem passível de superação (overruling) e nem de exceção (exception) seja o que for.

(1b) precedente vinculante derrotável (defeasibly): os precedentes são vinculantes, mas derrotáveis (defeasibly binding), sempre que não estejam sujeitos a superação (overruling), mas estejam sujeitos a exceções (bem ou mal definidas).

(1c) precedente vinculante suave (softly): os precedentes são suavemente vinculantes (softly binding), sempre que estejam sujeitos a superação (overruling) ou modificação, e também possam estar sujeitos a exceções.

2. força persuasiva de facto = Df. "um julgamento que não respeite a força do precedente, embora legal, está sujeito ao criticismo neste patamar e pode estar sujeito a revisão".

Duas variedades da força persuasiva de facto são separadas:

(2a) precedente persuasivo derrotável (defeasibly): precedentes são persuasivos derrotáveis, sempre que eles "deveriam ser aplicados, a menos que exceções sejam cabíveis (bem ou mal definidas) ".

(2b) precedente persuasivo prevalecente (outweighable): precedentes são persuasivo prevalecentes sempre que eles "deveriam ser aplicados, a menos que haja motivos contrários para não aplica-lo"."11

3. força justificatória complementar $=\mathrm{Df}$. precedentes possuem uma força justificatória complementar, sempre que a decisão subsequente onde ela não é mencionada, embora juridicamente justificada, não estiver

edents: a comparative study. Ashgate: Dartmouth, 1997. 461-479.

11 MACCORMICK, Neil; SUMMERS, Robert S. Apendix: final version of the common questions, comparative legal precedent study, september 1994, In: MACCORMICK, Neil; SUMMERS, Robert S. (Ed.). Interpreting precedents: a comparative study. Ashgate: Dartmouth, 1997. p. 554-555; uma visão ampla do escopo consta do ensaio de PECZENIK, A. The binding force of precedent. In: MACCORMICK, Neil; SUMMERS, Robert S. (Ed.). Interpreting precedents: a comparative study. Ashgate: Dartmouth, 1997. 461-479. 
"tão bem justificada" como estaria se o precedente fosse invocado. ${ }^{12}$

\section{4. meramente ilustrativa - ou outro valor pa-} recido $=$ Df. precedentes possuem a força de um mero exemplo, sempre que as decisões subsequentes, onde eles não são sequer mencionados, sejam tidos por jurídicos e bem justificados.

O Círculo de Bielefeld possui, como mencionado, a consideração mais sofisticada de uma rede de conceitos e distinções trabalhadas para capturar a maior variedade possível do fenômeno da relevância prática dos precedentes, melhorando nossa compreensão a respeito.

Mais do que isso, o valor teórico das observações do Círculo de Bielefeld brilha também sobre suas desvantagens, por elas serem, não obstante, instrutivas.

Eu percebo duas maiores desvantagens nas observações do Círculo de Bielefeld.

Primeiro, e talvez a mais séria desvantagem, refere-se a maneira como a força persuasiva de facto dos precedentes foi caracterizada. Neste ponto, uma linguagem normativa indevida foi utilizada: uma que seria mais conveniente quando estiver lidando com a relevância formal (ou de iure) dos precedentes (confira-se, por exemplo, onde é estipulado que "um julgamento que não respeite a força do precedente, embora legal, está sujeito ao criticismo neste patamar e pode estar sujeito a revisão", ou onde é estabelecido que um precedente possui força persuasiva quando ele "deveriam ser aplicados, a menos que haja motivos contrários para não aplica-lo"). Este ponto sugere que, talvez não seja "à prova d'agua" a distinção entre "vinculação formal" e força persuasiva de facto: ela não aponta, como dito em minhas observações anteriores $(\$ 5.1)$, as duas distinções ordenadas dimensões da relevância prática do precedente. A dimensão normativa desentendendo das normas legais positivas, por um lado; a dimensão empírica das práticas judiciais reais dependendo da tradição e da cultura jurídica, por outro lado.

A segunda desvantagem das observações do Círculo de Bielefeld refere-se a maneira de caracterização das

12 MACCORMICK, Neil; SUMMERS, Robert S. Apendix: final version of the common questions, comparative legal precedent study, september 1994, In: MACCORMICK, Neil; SUMMERS, Robert S. (Ed.). Interpreting precedents: a comparative study. Ashgate: Dartmouth, 1997. p. 554-555; uma visão ampla do escopo consta do ensaio de PECZENIK, A. The binding force of precedent. In: MACCORMICK, Neil; SUMMERS, Robert S. (Ed.). Interpreting precedents: a comparative study. Ashgate: Dartmouth, 1997. 461-479. três diferentes formas dos precedentes formalmente vinculantes. Neste ponto, possivelmente seria mais preferível uma imagem mais articulada (relativa, como veremos em seguida, a dois diferentes tipos de derrotabilidade), como uma ferramenta para o aprofundamento de nossa compreensão da realidade e capacidade classificatória. Tentarei esboçar uma tal imagem na parte seguinte, e a última delas, de meu texto.

\subsection{Oito sistemas ideais típicos de relevância formal}

Sobre a relevância de iure dos precedentes - ou melhor dizendo: da ratio decidendi de um precedente-julgamento, podem ser separados oito sistemas ideais tipos de relevância formal, basicamente através da forma de pensamento experimental:

(1) sistemas de relevância proibida.

(2) sistemas de relevância muito fracos argumentativamente

(3) sistemas de relevância fracos argumentativamente

(4) sistemas de relevância fortes argumentativamente

(5) sistemas de força vinculante fraca

(6) sistemas de força vinculante forte

(7) sistemas de força vinculante muito fortes

(8) sistemas de relevância discricionária

Observemos rapidamente cada um deles.

(1) sistemas de relevância proibida. Um sistema deste tipo é caracterizado pela proibição de qualquer relevância prática para qualquer precedente judicial. Em uma grafia ideal, eles representam o "degrau zero" da relevância prática para o precedente. Como uma medição como essa poderia ser realizada?

Vamos distinguir entre a relevância prática do lado de fora dos processos individuais, onde aos julgamentos são pronunciados (relevância prática externa) e do lado de dentro deles (relevância prática interna).

Para relevância prática externa, ela pode ser guiada por uma estrita regulação que:

(a) Exclui, a princípio, qualquer forma de expressão autorizativa de "precedentes", até mesmo aqueles persuasivos, de facto, pela proibição de qualquer referência a precedentes judiciais nas decisões (judicial opinions); e,

(b) Proibição, para tornar efetiva tal exclusão, de se realizarem publicações, repositórios, anotações e comentários de qualquer tipo, das decisões judiciais.

Isso significa que o precedente-julgamento seria 
condenado a uma vida secreta ciosamente guardada nos arquivos judiciais. Desta maneira, cada juiz tendo que decidir um caso seria, não seria capaz de extrair apoio de qualquer espécie das decisões pretéritas dos outros juízes: cada juiz estaria sozinho em defronte ao caso sob julgamento, munido apenas de seus livros jurídicos (códigos, regulamentos, e possivelmente textos jurídicos abstratos). E com relação ao fato de um juiz pedir aconselhamento e conversando com outros juízes, no mesmo local judicante, ou em outro local, sobre os casos que eles decidiram? Em um sistema de não relevância estrita, mesmo tais contatos entre juízes seria proibido.

Para relevância prática interna, ela pode ser guiada por uma estrita regulação, de acordo com o que o juiz de apelação deveria fazer sob o monto de um espeço véu da ignorância sobre a maneira que o caso fora decidido pelo juiz (ou tribunal) inferior. Deste modo, cada julgamento, embora em grau de apelação, torna-se totalmente novo, e sobre a mesma matéria.

Sistemas de "não-relevância" parecem estranhos para sensibilidades contemporâneas. Eles parecem, considerados todos os seus aspectos, profundamente irracionais como sistema legal disfuncional.

Por um lado, a relevância prática externa dos sistemas de proibição estrita dos precedentes parece resultar em uma cultura jurídica extremamente empobrecida. Para falarmos inicialmente do case-law, o lugar privilegiado onde os estatutos e outras regulamentações podem ser testados sobre seu sentido, escopo e determinação no local dos fatos reais dos casos; o case-law é, profundamente, uma das maiores agências do desenvolvimento do direito, por suas constantes adaptações às "necessidades" e "requerimentos" advindos da sociedade; o case-law proporciona ainda, um fórum a mais de princípio ao lado da arena política onde novas soluções e novos direitos podem ser trabalhados com a cooperação dos juízes, juristas e advogados. Tudo isso seria perdido numa arena rigorosa de um sistema que não atribua relevância aos casos passados.

Por outro lado, a relevância prática interna dos sistemas de proibição estrita dos precedentes pode resulta em uma total arbitrariedade na tomada de decisão judicial: devido ao princípio do véu da ignorância, cada juiz (em cada um dos vários graus de jurisdição) pode decidir um caso simplesmente através do cara ou coroa. Evidentemente o legislador pode impor aos juízes o dever de justificação das decisões, e tornar as decisões secretas, para ser lida apenas por uma corte de revisão, apenas, por assim dizer, em casos de suborno ou de negligência judicial grosseira. Mas isto pareceria tolo.

A propósito, sistemas reais (como o da França, p. ex.) desejam diminuir a relevância prática dos precedentes, sem incorrer em um (total) absurdo arranjo institucional, escolhido, como se sabe, uma trilha diferente: (a) eles extirparam a relevância forma - ou de iure, dos precedentes; (b) eles não proibiram, entretanto, nem os repositórios dos case-law julgados, e nem a literatura ou os argumentos e comentários sobre os casos; (c) como relevância interna, eles impuseram para quaisquer juízes o dever de justificação (como forma de controle da discricionariedade judicial), permitindo também aos juízes de graus superiores a lerem as decisões dos juízes de graus inferiores, mas não tornaram a holding das decisões de graus superiores não automaticamente vinculantes para as decisões de graus inferiores, aos quais os processos se referem de forma repetida.

(2) sistemas de relevância muito fracos argumentativamente. Nesse tipo de sistema, a doutrina (relevância externa) do direito positivo do precedente contém duas prescrições básicas:

(2a) seriam melhor aos juízes recuperarem - e mencionarem em suas opiniões, qualquer precedente relevante;

(2b) seria melhor aos juízes seguirem os precedentes relevantes, em ordem a promover os valores da segurança jurídica (certainty), previsibilidade (predictability) e a proteção das expectativas das pessoas.

As duas prescrições são atribuídas, entretanto, como meras recomendações para boas práticas judiciais. Nada desagradável segue-se após o seu desatendimento. De uma perspectiva formal, um julgamento onde estas recomendações não são cumpridas é perfeitamente jurídico e válido, sejam no que concerne ao seu conteúdo (substância), ou a sua adequação formal relativo a motivação (argumentação), embora este último fosse uma melhor peça de opinião jurídica se as recomendações houvessem sido seguidas.

Adequadamente, nós podemos considerar esses sistemas como caracterizados pela relevância formal que é, a um só tempo, argumentativa e muito fraca.

(3) sistemas de relevância fracos argumentativamente. Neste tipo de sistema, a doutrina (relevância externa) do direito positivo do precedente contém - novamente, duas prescrições básicas: 
(3a) os juízes devem recuperar, e mencionar em suas decisões, qualquer precedente relevante;

(3b) seria melhor aos juízes seguirem os precedentes relevantes, em ordem a promover os valores da segurança jurídica (certainty), previsibilidade (predictability) e a proteção das expectativas das pessoas.

Neste caso, a doutrina dos precedentes contém, por hipótese, dois ingredientes heterogêneos: uma norma de dever impositiva, e uma recomendação.

A violação do dever afeta a validade do julgamento: ele pode ser apelado, e revertido, neste ponto. Uma vez que o dever tenha sido cumprido, entretanto, o julgamento é legal e válido, mesmo embora a recomendação não tenha sido seguida - e o juiz, por exemplo, cita o precedente, mas decide julgar em sentido contrário, sem justificar argumentativamente, após ter citado os precedentes relevantes.

Sistemas como esse são caracterizados pela relevância de iure, isto é, a um só tempo: argumentativo e fraco. A presença de um precedente relevante, mesmo que alguém esteja apontando para uma solução diferente daquela efetivamente acolhida pelo juiz atual, deve ser citada; mas o juiz não possui o dever de argumentar os motivos pelos quais deixa de seguir o precedente citado. A distinção tácita (tacit distinguishing) e a superação tácita (tacit overruling) são perfeitamente legais.

(4) sistemas de relevância fortes argumentativamente. Um sistema garante forte relevância argumentativa, de iure, aos precedentes judiciais, quando sua doutrina (de relevância externa) do precedente contenha as seguintes prescrições:

(4a) os juízes devem recuperar, e mencionar em suas decisões, qualquer precedente relevante;

(4b) os juízes devem seguir os precedentes relevantes, a menos que forneçam razões "esmagadoras", "sérias", "boas", "fortes" e "prevalecentes" para se afastarem do precedente ou para afastá-lo (overruling).

Neste sistema, a doutrina do precedente contém, por hipótese, dois deveres. A violação de cada um deles afeta a validade da decisão, que pode ser apelada e revertida, por ambos os casos.

Nos termos do Círculo de Bielerfeld, este sistema seria, grosso modo, caracterizado como de "precedentes vinculantes suaves" (softly binding precedentes) - ou possivelmente, por força persuasiva prevalecente). Prefiro conceituar este tipo-ideal em termos de força dos precedentes fortemente argumentativos, de iure. Os preceden- tes impõem uma carga argumentativa aos juízes que deles querem se livrar (superação ou distinção): eles devem encontrar razões para apresentar uma ratio decidendi distinta, como sendo melhor, forte e mais adequada do que a anterior.

(5) sistemas de força vinculante fraca. Um sistema garante força vinculante fraca, ou uma derrotabilidade aberta em termos de relevância aos precedentes judiciais, sempre que sua doutrina (de relevância externa) do precedente contenha as seguintes prescrições:

(5a) os juízes devem recuperar, e mencionar em suas decisões, qualquer precedente relevante;

(5b) os juízes devem seguir os precedentes relevantes, mesmo que forneçam razões "esmagadoras", "sérias", "boas", "fortes" e "prevalecentes" para se afastarem do precedente ou para afastá-lo (overruling).

(5c) os juízes podem, no entanto, deixar de seguir o precedente relevante, se o caso sob exame cair nas seguintes exceções pertencentes a uma lista aberta, que o juiz da causa por ele mesmo, contribuir para complementar (por exemplo, casos vagamente paradigmáticos, abertos à analogia e extensões a fortiori).

$\mathrm{Na}$ perspectiva do Círculo de Bielerfeld, como observamos acima (\$5.2), duas situações são distinguidas - precedentes vinculantes derrotáveis e precedentes persuasivos derrotáveis - compartilhando com o precedente-holding o fato de estarem sujeitos a exceções, sejam elas bem definidas ou não.

Penso, entretanto, que numa perspectiva analítica de variados tipos e sistemas de relevância de iure dos precedentes judiciais, a situação onde um precedente-holding esteja sujeito a "exceções bem-definidas" deve cuidadosamente ser separado de situações em que ele esteja sujeito a "exceções não-bem-definidas".

Para tornas as coisas mais tranquilas (mas, evidentemente o modelo pode ser tornado mais complexo e articulado, para ser mais realista), assumirei o seguinte: exceções para um precedente-holding são "bem-definidas" se (mas apenas se) elas forem um grupo fechado de palavras precisas. Contrário senso, exceções ao precedente-holding não serão bem definidas se (e apenas se) elas forem um grupo de palavras vagas e abertas.

A relevância argumentativa relaciona-se com a possibilidade de superação (overruling - tácito, onde é muito fraco ou fraco; e necessariamente explícito, onde é forte). Força vinculante tem a ver com a distinção (distinguishing, distinção-derrotabilidade, distinção-interna, 
exceção-distintiva), existente onde a superação (overruling) é formalmente excluída (como p. ex. por uma norma positiva como no $5 b)$.

Agora, para qualquer efeito prático, há também a diferença entre a relevância argumentativa forte, e como iremos observar, uma força vinculante forte ou muito forte; a diferença, entretanto, aparenta ser um pouco obscura quando a relevância argumentativa forte é comparada com a força vinculante fraca. Adicionando algumas exceções por sua própria intervenção, o juiz pode chegar aquilo que ele não alcançaria através do overruling.

(6) sistemas de força vinculante forte. Um sistema garante força vinculante forte, ou uma derrotabilidade fechada em termos de relevância aos precedentes judiciais, sempre que sua doutrina (de relevância externa) do precedente contenha as seguintes prescrições:

(6a) os juízes devem recuperar, e mencionar em suas decisões, qualquer precedente relevante;

(6b) os juízes devem seguir os precedentes relevantes, mesmo que forneçam razões "esmagadoras", "sérias", "boas", "fortes" e "prevalecentes" para se afastarem do precedente ou para afastá-lo (overruling).

(6c) os juízes podem, no entanto, deixar de seguir o precedente relevante, se o caso sob exame cair nas seguintes exceções pertencentes a um grupo fechado de palavras precisas.

A força vinculante dos precedentes, em sistemas deste tipo, é mais forte dos que o mencionado anteriormente; um juiz pode derrotar um precedente-holding se (e apenas se) a exceção detenha determinado conjunto: i.e., uma exceção a qual, por hipótese, eles não possam criar ou modificar (mas dentro das franjas inevitáveis da vagueza vindo juntamente com cada expressão da linguagem ordinária).

(7) sistemas de força vinculante muito fortes. Um sistema garante força vinculante muito forte, ou uma força vinculante absoluta em termos de relevância aos precedentes judiciais, sempre que sua doutrina (de relevância externa) do precedente contenha as seguintes prescrições:

(7a) os juízes devem recuperar, e mencionar em suas decisões, qualquer precedente relevante;

(7b) os juízes devem seguir os precedentes relevantes, mesmo que forneçam razões "esmagadoras", "sérias", "boas", "fortes" e "prevalecentes" para se afastarem do precedente ou para afastá-lo (overruling). (7c) os juízes devem observar e preservar os precedentes relevantes como não sujeitos a exceções de qualquer espécie.

(8) sistemas de relevância discricionária. Finalmente, um sistema relevância-discricionária, em termos de relevância aos precedentes judiciais, sempre que sua doutrina (de relevância externa) do precedente contenha a seguinte prescrição:

(8a) os juízes podem dar aos precedentes qualquer posição que eles achem apropriada para o caso - e.g., eles podem se sentir absolutamente limitados por algum precedente, ou considera-lo possuidor de alguma força vinculante fraca ou forte, ou mesmo considera-lo possuidor de força argumentativa forte, fraca ou muito fraca, e mesmo não atribuir nenhuma relevância qualquer que seja a decisão para os casos subsequentes.

Eu não sei se algum sistema legal é, ou algum dia tenha sido assim. Existem, no entanto, experiência jurídicas de práticas judiciais as quais, de um ponto de vista externo ou sociológico podem ser descritas como informadas pela doutrina da relevância discricionária, para os juízes assumirem isso, ou algo parecido com isso, como uma doutrina de iure em sua tomada de decisões.

Para concluir, eu gostaria de fazer três observações.

(1) as considerações acima podem ser tornadas mais complexas, através da adição (e combinação) dos ideais típicos de sistemas de precedentes, de relevância de iure, nas dimensões vertical e horizontal que mencionei anteriormente $(\$ 5.1)$.

(2) os sistemas acima descritos são tipos ideais. Isto significa que seus poderes explicativos e classificatórios sempre dependerão de ajustes para serem construídos sob a luz da experiência jurídica que será objeto de investigação.

(3) doutrinas do precedente, limitadas e demandantes, como possam ser no paper, sempre devem ser tomadas ao estilo "salva interpretatione", isto é: contra um pano de fundo de técnicas interpretativas que juristas e juízes estão acostumados, e/ou utilizadas no sistema jurídico para identificação e relação de imagem com as razões de decidir que possuam valor de precedente.

\section{Referências}

MACCORMICK, Neil; SUMMERS, Robert S. Apendix: final version of the common questions, comparative legal 
precedent study, september 1994, In: MACCORMICK, Neil; SUMMERS, Robert S. (Ed.). Interpreting precedents: a comparative study. Ashgate: Dartmouth, 1997. p. 554555.

MACCORMICK, Neil; SUMMERS, Robert S. (Ed.). Interpreting precedents: a comparative study. Ashgate: Dartmouth, 1997.

MOHANAN, K. P.; MOHANAN, Tara. Resoning.
PECZENIK, A. The binding force of precedent. In: MACCORMICK, Neil; SUMMERS, Robert S. (Ed.). Interpreting precedents: a comparative study. Ashgate: Dartmouth, 1997. 461-479.

SCHAUER, Frederick. Why precedent in law and elsewher is not totally or even substaintially: about analogy. In: Perspectives on Psychological Science, v. 3, n. 6 p. 454460, 2008. 